\title{
Development in the prediction method for transverse crack growth rate using FEM
}

\author{
M. Hosoda, H. Kataoka \& T. Deshimaru \\ Department of Track Structures and Components, \\ Railway Technical Research Institute, Japan
}

\begin{abstract}
The maintenance work on rail defects, especially squat, is very important to ensure railway safety. As to the ultrasonic flaw detection of the squat, it is not easy to identify the exact position of the crack tip and the depth of transverse crack, due to the reflection of the incident ultrasonic wave at the horizontal crack generated in the rail head. Therefore, the study on the mechanism of crack growth is very helpful in making a maintenance plan. In this paper, the authors proposed a test method for crack growth with a full-scale test rail. The authors also compared the FEM analysis results for an estimation of the Stress Intensity Factor (SIF) and the transverse crack growth rate with the test results, and proposed the prediction method of the transverse crack growth rate using FEM under various actual track conditions.
\end{abstract}

\section{Introduction}

Squat is a typical type of fatigue crack originating at the surface of a rail head. In the first stage of crack propagation, a horizontal crack grows beneath the surface of the rail head. And in the second stage, transverse cracks branch from the horizontal crack and grow in a direction toward a rail base (shown in Figure 1). The properties of transverse crack growth have been researched and reported by Kashiwaya and Ishida [1]. A lot of sophisticated crack propagation models have been proposed so far [2-8]. Generally, elemental test pieces taken from a rail head were used, so the properties of transverse crack growth on a full-scale rail have not been so far validated enough. Therefore, the authors firstly proposed the test method for crack growth with a full-scale test rail and obtained a crack growth rate experimentally. Secondly, the authors compared the FEM analysis 
results for an estimation of the Stress Intensity Factor (SIF) and transverse crack growth rate with the test results. Finally, the authors proposed the prediction method of the transverse crack growth rate using FEM under various actual track conditions.

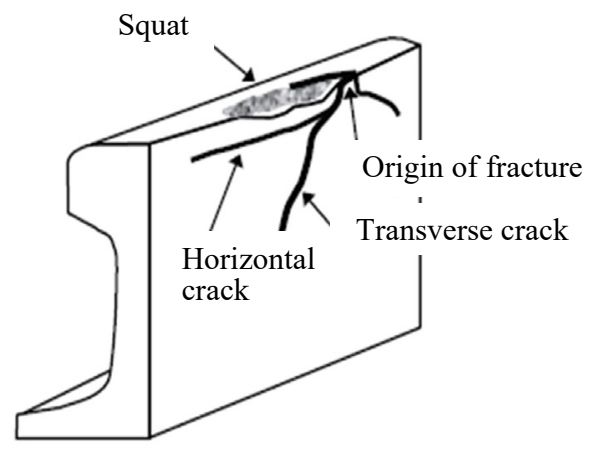

Figure 1: $\quad$ Squat and transverse crack.

\section{Test method of transverse crack growth considering bending, and thermal tension}

\subsection{Test method}

In order to confirm crack growth rate, a transverse crack growth test was carried out on a full scale rail with artificially-processing (semicircle slit) and generated initial crack of squats. The test was carried out with a rail bending fatigue testing machine, in such a way that vertical cyclic loading and horizontal static loading was applied simultaneously. The specimen was placed on the test rack (shown in Figure 2) and loaded with axial tensile force in the longitudinal direction so as to yield positive bending stress amplitude in the rail head under the loading point. The amplitudes were varied periodically to ascertain the crack growth rates from the observed beach mark (shown in Figure 3). The test condition is given in Table 1. Two kinds of tensile force were set in consideration of the force generated by the temperature alteration from setting temperature of CWRs. The temperature range was 25 or 50 degrees in Celsius. It was known that the transverse crack would grow in inclined direction from a cross-section of rail, but the cause was not obvious. It was also considered that contact force had influence on crack growth rate when initial crack was put on the loading position. Therefore, analysis before the loading test was carried out, and it has been understood that the stress in the direction of the normal to the surface inclined at 30 degrees with respect to the axis of the rail was the largest at a position about $20 \mathrm{~mm}$ away from the loading position. Therefore, the test rails were set so that there was a distance of $20 \mathrm{~mm}$ between the initial crack and the loading point so as to reproduce crack growth in a forward direction. 


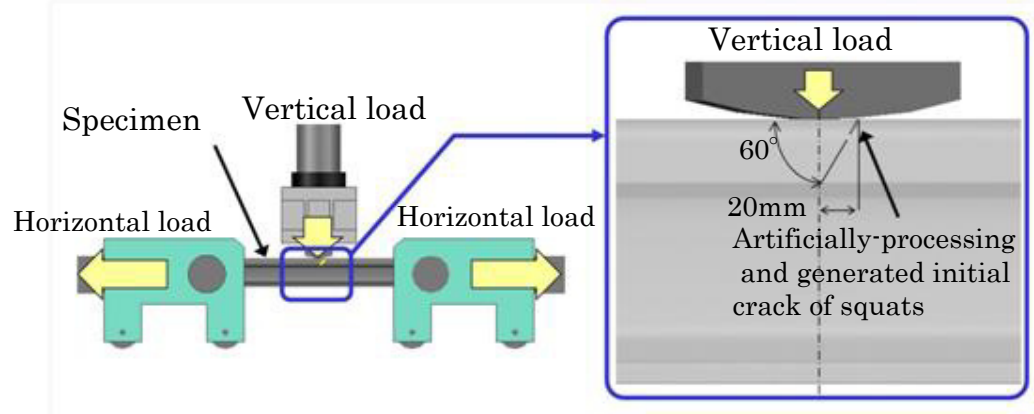

Figure 2: Overview of transverse crack growth test.

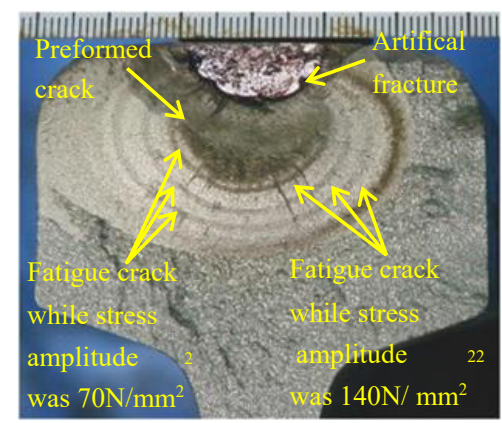

Figure 3: Example of beachmark on fracture faces of test specimens.

Table 1: $\quad$ Test arrangement condition of crack growth.

\begin{tabular}{|c|c|c|c|c|}
\hline \multicolumn{3}{|c|}{ Rail type } & \multicolumn{2}{|c|}{ JIS $50 \mathrm{kgN}$} \\
\hline \multicolumn{3}{|c|}{ Test method } & three-poi & $\mathrm{nt}$ bending test \\
\hline \multicolumn{3}{|c|}{ Tensile force } & $754 \mathrm{kN}$ & $377 \mathrm{kN}$ \\
\hline \multirow{4}{*}{$\begin{array}{l}\text { Total stress } \\
\text { amplitude in rail } \\
\text { base and cycles }\end{array}$} & \multirow{2}{*}{1} & $\mathrm{a}$ & \multicolumn{2}{|c|}{$140 \mathrm{~N} / \mathrm{mm}^{2}, 1.0 \times 10^{5}$ cycles } \\
\hline & & $\mathrm{b}$ & \multicolumn{2}{|c|}{$70 \mathrm{~N} / \mathrm{mm}^{2}, 2.0 \times 10^{5}$ cycles } \\
\hline & $?$ & $\mathrm{a}$ & \multicolumn{2}{|c|}{$170 \mathrm{~N} / \mathrm{mm}^{2}, 1.0 \times 10^{5}$ cycles } \\
\hline & 2 & $\mathrm{~b}$ & \multicolumn{2}{|c|}{$105 \mathrm{~N} / \mathrm{mm}^{2}, 2.0 \times 10^{5}$ cycles } \\
\hline \multicolumn{3}{|c|}{ Frequency } & \multicolumn{2}{|r|}{$3 \mathrm{~Hz}$} \\
\hline
\end{tabular}




\subsection{Test results}

The result of the transverse crack growth test is as follows (shown in Table 2):

(a) Transverse crack progressed, in the state of bending compression induced by vertical cyclic loading, under tensile force in longitudinal direction. Furthermore, the authors also reproduced a transverse crack which grew in inclined plane of rail head (shown in Figure 4).

(b) Under conditions of axial tensile force of $754 \mathrm{kN}$ applied to $50 \mathrm{kgN}$ rail, four out of nine test rail specimen broke.

(c) The beach mark of fracture face of broken test specimen was visible and the relationship between the number of cycles and crack depth was apparent. The authors calculated transverse crack growth rate by crack depth divided the number of cycles. The test specimens which were not broken were broken forcibly after the tests, but the beach mark of fracture face was not visible. Therefore, the authors calculated transverse crack growth rate by total depth divided the number of the total cycles. In the test result, the highest transverse crack growth rate was $0.59 \times 10^{-4} \mathrm{~mm}$ cycle.

Table 2: $\quad$ Result of crack growth test.

\begin{tabular}{|c|c|c|c|c|}
\hline $\begin{array}{c}\text { Tensile } \\
\text { force } \\
(\mathrm{kN})\end{array}$ & $\begin{array}{c}\text { Total stress } \\
\text { amplitude } \\
\left(\mathrm{N} / \mathrm{mm}^{2}\right)\end{array}$ & $\begin{array}{c}\text { Accumulative } \\
\text { cycles } \\
\left(\times 10^{4}\right)\end{array}$ & $\begin{array}{c}\text { Crack growth } \\
\text { rate } \\
\left(\mathrm{mm} / \times 10^{4}\right) \\
\end{array}$ & $\begin{array}{l}\text { artificial or } \\
\text { generated } \\
\text { crack }\end{array}$ \\
\hline \multirow{9}{*}{754} & \multirow{7}{*}{70,140} & 115.5 & 0.26 & \multirow{3}{*}{ artifical } \\
\hline & & 124.3 & 0.46 & \\
\hline & & 100 & 0.59 & \\
\hline & & 161.1 & 0.08 & generated \\
\hline & & \multirow{7}{*}{ No fracture } & 0.01 & \multirow{7}{*}{ artifical } \\
\hline & & & 0 & \\
\hline & & & 0.05 & \\
\hline & \multirow{2}{*}{105,170} & & 0.04 & \\
\hline & & & 0.06 & \\
\hline \multirow{2}{*}{377} & \multirow{2}{*}{105,170} & & 0 & \\
\hline & & & 0 & \\
\hline
\end{tabular}

In the results, considerable unevenness occurred regarding the transverse crack growth rate. It is speculated that one of the factor of the cause for the unevenness is the internal residual stress of rail head. The authors presumed two cases of condition of the residual stress. These are as follows:

Case 1) Tensile residual stress occurred.

Case 2) Little residual stress occurred.

It was reported that a new rail of JIS $50 \mathrm{kgN}$ has little tensile internal residual stress at its rail head, and a used rail to which the train load was applied has tensile internal residual stress at its rail head (e.g. Kashiwaya and Ishida [1], 
Ochi and McEvily [9]) In case 1, the authors speculated that almost all compression stress amplitude by vertical load contributes to transverse crack growth rate under tensile force and residual stress, and transverse crack growth rate becomes higher (shown in Figure 5(a)). In case 2, a part of compression stress amplitude by vertical load contributes to transverse crack growth rate and transverse crack growth rate becomes lower (shown in Figure 5(b)).

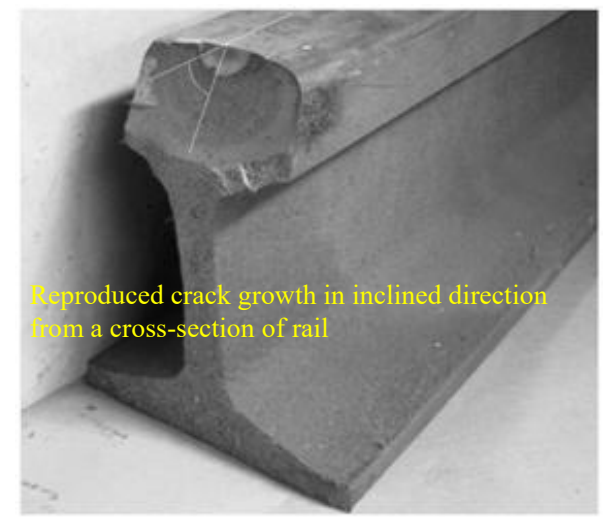

Figure 4: Example of fracture faces of test specimens.

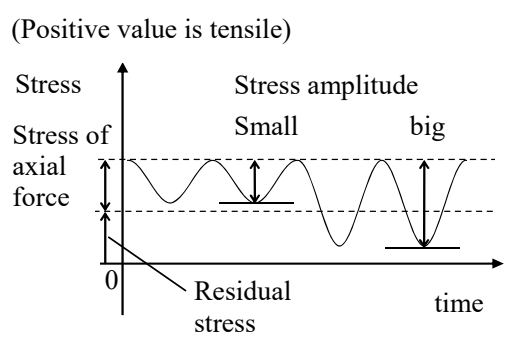

(a) Case 1

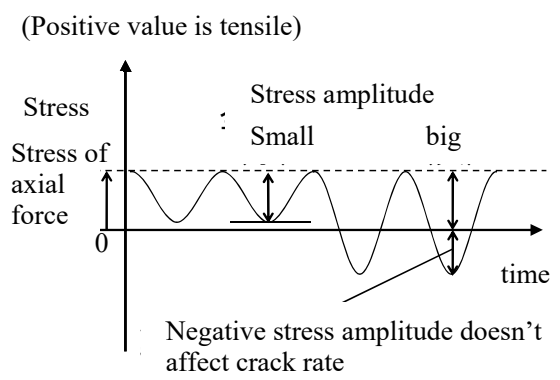

(b) Case 2

Figure 5: Speculated condition of stress in rail head.

\section{Verification of FEM analysis model by comparison with test result of transverse crack growth test}

Static analysis by the FEM model (shown in figure 6) of the test rail were carried out to estimate the transverse crack growth rate to be compared with test result. 2 case static analyses were carried for estimation crack growth rate. 
Case 1: The FEM model was loaded with axial tensile force $754 \mathrm{kN}$ (distributed equal intervals) and with residual stress $50 \mathrm{~N} / \mathrm{mm} 2$ in longitudinal direction.

Case 2: The FEM model are loaded with vertical load $190 \mathrm{kN}$ (equivalent to bending stress $140 \mathrm{~N} / \mathrm{mm}^{2}$ in rail base).

The shape of crack was assumed to be a transverse crack and depth $25 \mathrm{~mm}$, angle 60 degrees.

The authors adopted the prediction method based on linear fracture mechanics for estimating crack growth rate. The elicitation process is as follows:

(a) Calculate Stress Intensity Factor (SIF) and stress at crack tip by the FEM model.

(b) Calculate Effective Stress Intensity Factor Range (ESIFR).

(c) Calculate crack growth rate by substituting ESIFR for the equation of fatigue crack propagation law.

An experimental test of elemental test pieces was already performed and the relationship between ESIFR and crack growth rate was revealed. The equation of the crack growth model was as follows:

$$
d a / d N=10^{-11}(\Delta \text { KIeff })^{3}
$$

where $a$ is a crack length, $N$ is the number of stress cycles and $\Delta$ KIeff is ESIFR. In this study, crack growth rate is estimated by this method.

As a result, the transverse crack growth rate was $2.29 \mathrm{~mm}$ per $1.0 \times 10^{4}$ cycles while the ESIFR was $28.4 \mathrm{MPa} \cdot \mathrm{m}^{1 / 2}$. This ESIFR, when multiplied by a correction coefficient of 0.6 , is the highest crack growth rate in this test result.

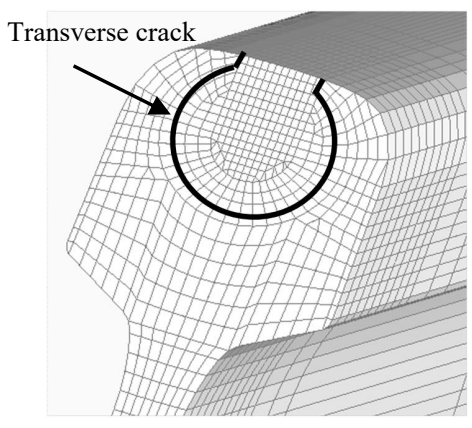

(a) Fracture face

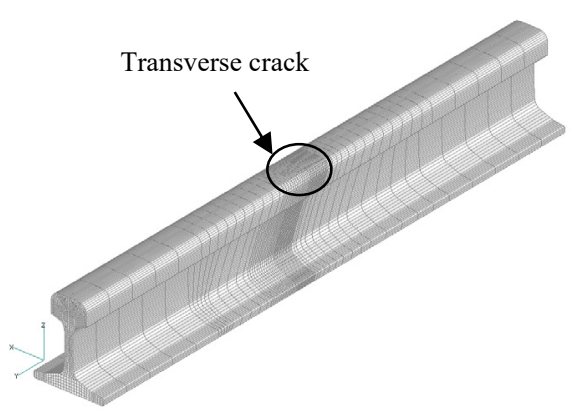

(b) Overview

Figure 6: Test rail model of FEM. 


\section{Development on prediction method of Transverse Crack Growth Rate using FEM}

The authors verified the FEM model discussed in Section 3 by applying the prediction method. Therefore, SIF was estimated by FEM model simulating a from real crack shape of the track structure. Track structure of FEM model has 14 sleeper and transverse crack set at the center in the rail length direction (shown in figure 7). Crack shape assumed real crack and set transverse cracks branched from horizontal cracks. The transverse crack growth rate was obtained by multiplying the estimated axial tensile force and rail bending stress by a correction coefficient. In this study, a prediction method of estimating the crack growth rate was proposed as shown in figure 8.

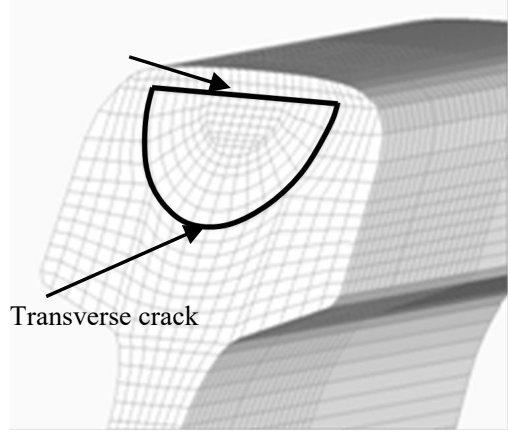

(a) Actual squat model

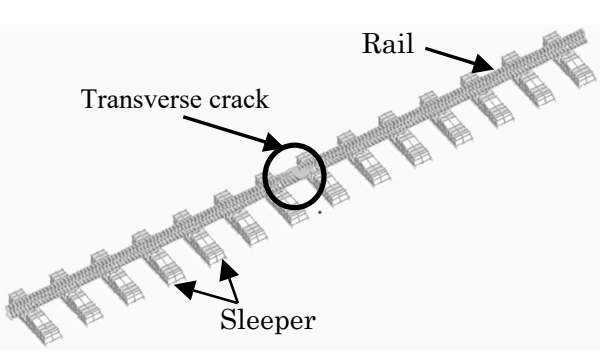

(b) Track panel model

Figure 7: FEM model for the prediction of the transverse crack growth rate.

Firstly, initial crack shape in railhead was set and bending stress in rail head was calculated based of vehicle loads and track structure conditions. Next, SIF and ESIFR were estimated in consideration of effects of residual and thermal stress occurring in rail head in addition to bending stress. This result was applied to Eq. (1) and crack growth rate was searched, so as to increase the depth of crack. The above-mentioned computation was executed repeatedly, and terminated when ESIFR was greater than the predetermined value. By using this tool, the authors calculated transverse crack growth rate tentatively, and show an estimated conditions of the calculation are as shown in Table3. The details of consideration which the authors took into when applying the prediction methods are as follows.

a) It was also considered that a residual stress of about $75 \mathrm{~N} / \mathrm{mm}^{2}$ in applied at the center of rail head.

b) It was considered that the daily average temperature changes over a year and the temperature changes according to the normal distribution for a day. 
c) Rail bending stress by the train load was considered based on the $100 \mathrm{~mm}$ chord rail surface irregularity. Rail surface irregularity is a drop of $0.25 \mathrm{~mm}$ or $0.50 \mathrm{~mm}$ on a $100 \mathrm{~mm}$ chord

The authors show an estimation result in Figure 9. The passage tonnage advancing the crack depth from $15 \mathrm{~mm}$ to $35 \mathrm{~mm}$ under this estimated condition is 57-80 million gross tonnages. These results could change accounting to the assumed driving condition of the vehicle and track condition.

Horizontal crack

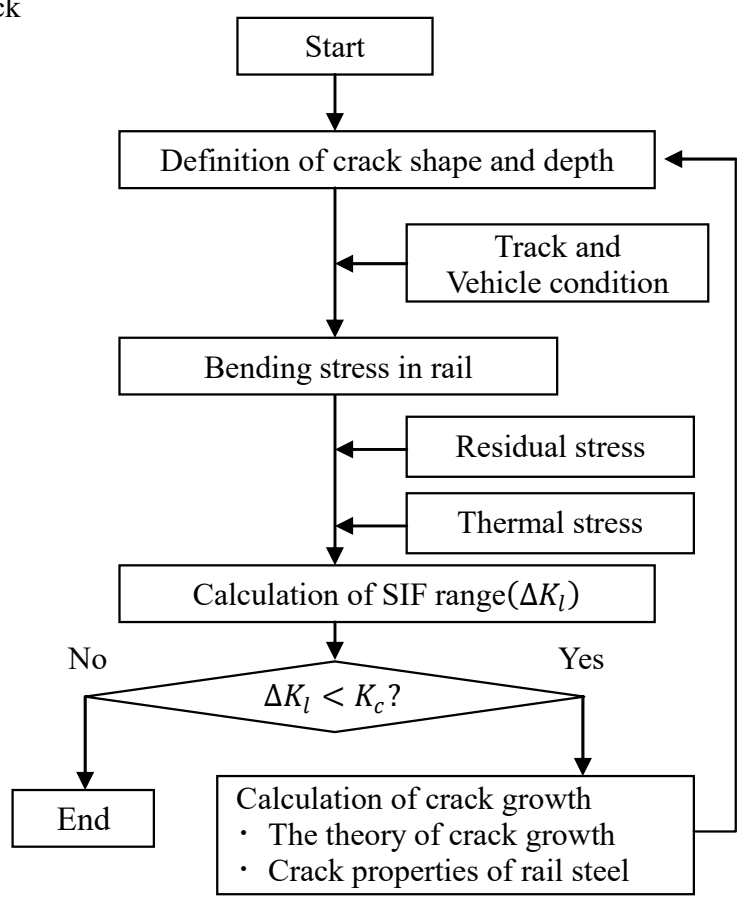

Figure 8: Flowchart for prediction of transverse crack growth.

Table 3: Prediction transverse crack growth estimated condition.

\begin{tabular}{|c|c|}
\hline Rail type & JIS 50kgN,60kg \\
\hline Track condition & Narrow gage, Ballast \\
\hline Vehicle condition & $\begin{array}{c}\text { Limited express } \\
\text { (Staticload }=58.7 \mathrm{kN}, \\
\text { Speed }=130 \mathrm{~km} / \mathrm{h})\end{array}$ \\
\hline $\begin{array}{c}\text { Average temperature of a year } \\
\text { chantity of the temperature } \\
\text { change amount of a year }\end{array}$ & $\pm 16^{\circ} \mathrm{C}$ \\
\hline $\begin{array}{c}\text { Standard deviation of } \\
\text { temperature of a day }\end{array}$ & $6.3^{\circ} \mathrm{C}$ \\
\hline
\end{tabular}




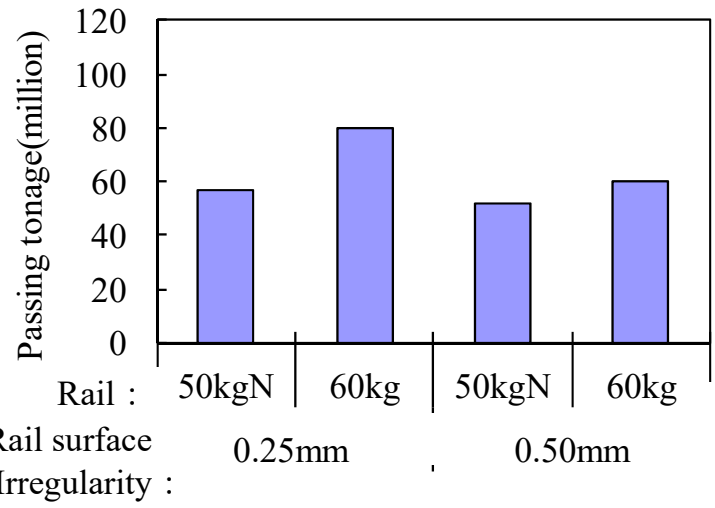

Figure 9: Estimated result.

\section{Conclusion}

In this paper, the authors proposed a test method for crack growth with full-scale test rail. Also, comparing the results obtained by some crack growth models with the test results obtained by the proposed test method, the prediction method of transverse crack growth rate under various actual track conditions was developed.

(a) To investigate the crack growth rate, rail bending fatigue tests were carried out using full scale sample rails taken out of actual track. Furthermore, the authors also reproduced a transverse crack which grew on inclined plane of rail head and derived exact crack growth rate from observation of the beach mark on fracture face. As a result of the test, the highest transverse crack growth rate was $0.59 \times 10^{-4} \mathrm{~mm}$ per cycle.

(b) The authors proposed the prediction method of transverse crack growth rate using FEM. The initial crack shape was set, axial tensile force and rail bending stress were calculated in consideration of track condition, and Stress Intensity Factor (SIF) and transverse crack growth rate was estimated by FEM model. Also, the authors proposed the prediction method of transverse crack growth rate under various actual track conditions was developed.

\section{References}

[1] K. Kashiwaya, M. Ishida, Prediction Model of Growth Rate of Rail Transverse Crack, Journal of Railway Mechanics, Japan Society of Civil Engineers, Vol. 7, 2003.

[2] M. Kaneta, H, Yatuszaka, Y. Murakami, Mechanism of crack growth in lubricated rolling/sliding contact, ASLE Trans. 28, 1985.

[3] S. Bogdanski, M.W. Brown, Modeling the three dimensional behaviour of shallow rolling contact fatigue cracks in rails, Wear 253(1-2), 2002, pp. 1725 . 
[4] M. Kanteta, Y. Murakami, Propagation of semi-elliptical surface cracks in lubricated rolling/sliding elliptical contacts, J. Trib. ASME 113, 1991, pp. 270-275.

[5] L.M. Keer, T.M. Farris, R.K. Steele, On some aspects of fatigue crack growth in rails induced by wheel/rail contact loading, in: Proceedings of the 2nd International Symposium on contact Mechanics and Wear of Wheel/Rail Systems, URI, University of Waterloo Press, 1986, pp. 83-92.

[6] A.F. Bower, The influence of crack face friction and trapped fluid on surface initiated rolling contact fatigue cracks, J. Trib. ASME 110, 1998, pp. 704 711.

[7] D.I. Fletcher, J.H. Beynon, A simple method of stress intensity factor calculation for inclined surface-breaking cracks with crack face friction under contact loading, in: Proceedings of the Imech E, Part J, J. Eng. Tribol., 1999, pp. 481-486.

[8] M. Akama, Fatigue crack growth under mixed loading of tensile and inplane shear modes, Q. Rep. RTRI 44, 2003, pp. 65-71.

[9] Y. Ochi, A.J. McEvily: An evaluation of fatigue crack growth and fracture toughness characteristics in rail steels Transactions of the JSME, Japan Society of Mechanical Engineers, Vol. 53, 1987, pp. 1273-1279. 